\title{
Primary Frequency Response from Offshore Wind Farms Connected to HVdc via Diode
} Rectifiers

Saborío-Romano, Oscar; Bidadfar, Ali; Sakamuri, Jayachandra Naidu; Göksu, Ömer; Cutululis, Nicolaos Antonio

\section{Published in:}

Proceedings of the 13th IEEE PowerTech Milano 2019: Leading innovation for energy transition

Link to article, DOI:

10.1109/PTC.2019.8810907

Publication date:

2019

Document Version

Peer reviewed version

Link back to DTU Orbit

Citation $(A P A)$ :

Saborío-Romano, O., Bidadfar, A., Sakamuri, J. N., Göksu, Ö., \& Cutululis, N. A. (2019). Primary Frequency Response from Offshore Wind Farms Connected to HVdc via Diode Rectifiers. In Proceedings of the 13th IEEE PowerTech Milano 2019: Leading innovation for energy transition IEEE. https://doi.org/10.1109/PTC.2019.8810907

\section{General rights}

Copyright and moral rights for the publications made accessible in the public portal are retained by the authors and/or other copyright owners and it is a condition of accessing publications that users recognise and abide by the legal requirements associated with these rights.

- Users may download and print one copy of any publication from the public portal for the purpose of private study or research.

- You may not further distribute the material or use it for any profit-making activity or commercial gain

- You may freely distribute the URL identifying the publication in the public portal 


\title{
Primary Frequency Response from Offshore Wind Farms Connected to HVdc via Diode Rectifiers
}

\author{
Oscar Saborío-Romano $^{(\mathbb{D}}$, Ali Bidadfar ${ }^{(\mathbb{D})}$, Jayachandra N. Sakamuri ${ }^{(\mathbb{D})}$, Ömer Göksu ${ }^{(\mathbb{D}}$, Nicolaos A. Cutululis ${ }^{(\mathbb{D})}$ \\ Department of Wind Energy \\ Technical University of Denmark \\ Ris $\emptyset$ Campus, Roskilde, Denmark \\ Email: osro@dtu.dk
}

\begin{abstract}
Diode rectifiers have been gaining traction as a viable alternative for connecting offshore wind farms (OWFs) to HVdc networks. However, before technical connection requirements compatible with such solutions can be determined, more studies are needed to assess their capabilities to contribute to the secure operation of the networks linked to them. This study assesses the capability of such an OWF to provide support to an onshore ac network by means of primary frequency response (PFR). A semi-aggregated OWF representation is considered in order to examine the dynamics of each grid-forming wind turbine (WT) within a string when providing PFR. Simulation results corroborate that such an OWF can indeed provide PFR, while its grid-forming WTs share the reactive power and keep the offshore frequency and voltages within their normal operating ranges.
\end{abstract}

Index Terms-Diode-rectifier-based HVdc transmission, frequency support, grid-forming wind turbine control, offshore wind energy integration, primary frequency response

\section{INTRODUCTION}

Electrical infrastructure connecting offshore wind farms (OWFs) with the onshore networks is needed to exploit Europe's offshore wind resources fully. To date, most OWFs export their production via HVac, and only a few are connected through HVdc [1]. The amount of HVdc-connected OWFs, however, is widely expected to increase, as their size and distance from shore increase and the associated costs decrease [2], [3].

$\mathrm{HVdc}$ transmission technology using voltage source (forced/self-commutated) converters (VSCs), based on insulated-gate bipolar transistors, has undergone great development since first introduced in 1997 [4]. Such HVdc transmission solutions still have higher losses and overall costs than the more common, mature ones employing (phase-controlled) line-commutated converters, based on thyristors (in a current source converter topology), which are largely used for bulk power transmission [3], [5]. However, VSC-based HVdc transmission (VSC$\mathrm{HVdc}$ ) offers advantages such as smaller footprints, independent control of active and reactive power, fast reversibility of active power flow, and the (grid-forming) capability to form ac networks, i.e. to control their ac-side voltage magnitude and frequency [4]. Owing to such advantages, the use of

This work has received funding from the European Union's Horizon 2020 research and innovation programme under grant agreement No 691714.
VSC-based offshore HVdc terminals has made it possible to develop HVdc-connected OWFs with the prevailing gridfollowing approach to controlling wind turbines (WTs), in which WTs rely on other (grid-forming) units forming their ac network.

Recently proposed, (uncontrolled, line-commutated) diode rectifiers (DRs) have been gaining traction as a viable alternative for connecting OWFs to HVdc networks [6]-[11]. DR-based offshore HVdc terminals offer advantages such as smaller footprints, lower costs, higher efficiency and higher reliability [8], [10]. However, they lack the grid-forming capability of VSCs, so that their use relies on delegating such responsibility to the WTs. This requires fundamentally different WT and WF control schemes, changing their control approach from that of grid-following units to that of gridforming units [6], [9].

The capability of VSC-HVdc-connected OWFs to provide frequency support (FS) to onshore ac networks has been investigated in [12]-[14] for two (point-to-point), three and four terminal HVdc networks, respectively. Moreover, current technical connection requirements for $\mathrm{HVdc}$-interconnected offshore generation are based on the same paradigm of gridforming controllable offshore HVdc terminals [15], [16]. Such requirements need to be adapted so as to include the possibility of having uncontrollable offshore $\mathrm{HVdc}$ terminals, if OWF connection concepts such as DRs are to be deployed. However, before compatible requirements can be determined, more studies are needed to assess the capabilities of such solutions to contribute to the secure operation of the networks linked to them [17], [18].

The present study assesses the capability of an OWF to provide FS to an onshore ac network, when connected through an HVdc link having a DR-based offshore terminal and a VSCbased onshore terminal. Focus is given to primary frequency response (PFR), based on an active-power-frequency droop, with the reserves from preventively curtailed operation considered as the source of additional active power during onshore underfrequency events. The study also examines the compatibility of corresponding higher-level controls previously devised for VSC-connected OWFs [12]. Through such controls, the OWF modifies its active power output according to the onshore frequency signal directly communicated to it [19]. 


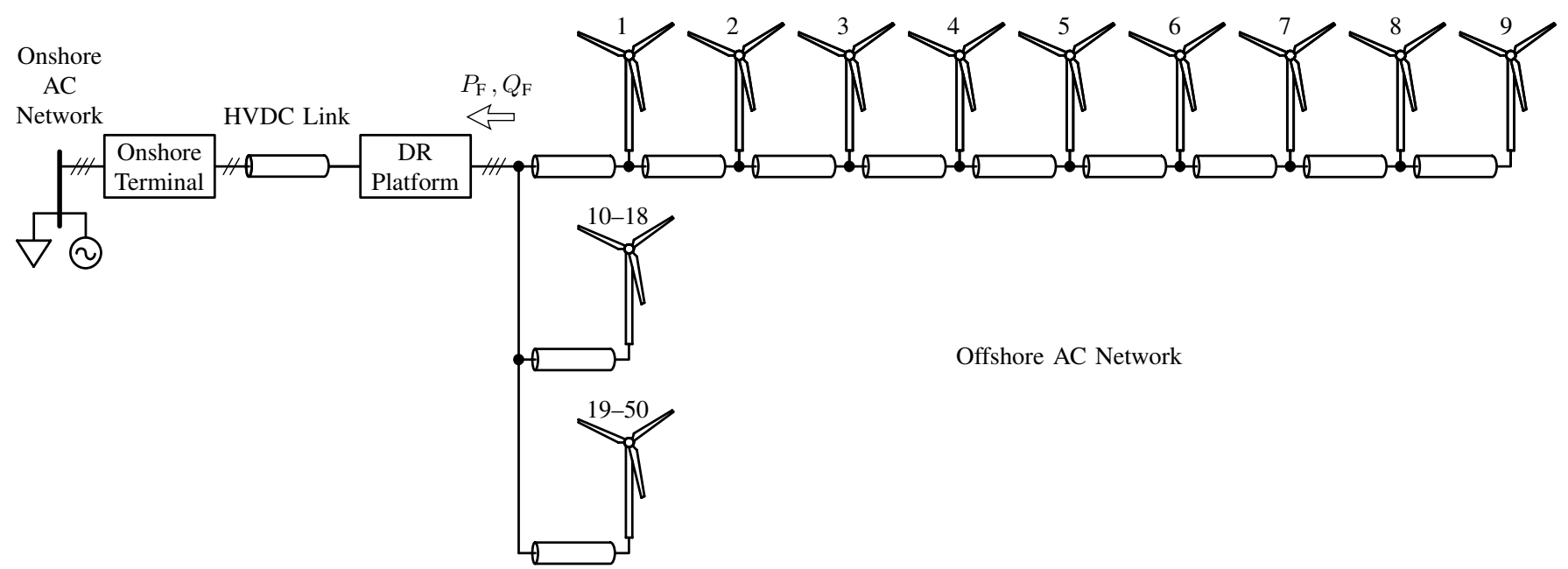

Fig. 1. Overview of the studied system

Previous work [20], [21] was conducted using models and grid-forming WT front-end converter (FEC) controls based on those in [6]-[8] and an aggregated representation of the OWF as a single equivalent WT. Such controls rely on communication for a centralised voltage control and do not deal with the synchronisation of the WT FECs, whereas the aggregated OWF model does not provide enough insight into the dynamics within the OWF. This study uses more detailed models based on those in [19], and a semi-aggregated representation of the OWF. Such OWF representation provides insight into the dynamics of the WTs within a string by representing them in detail, while keeping reasonable simulation times. Moreover, the considered grid-forming WT FEC controls are based on those in [11], which rely solely on local measurements and enable the synchronisation of the WT FECs by means of a distributed phase-locked-loop-based frequency control algorithm.

The rest of the paper is organised as follows. In Section II, the investigated system is described and the main control algorithm is detailed. In Section III, some of the considered cases are described, and corresponding simulation results are presented and discussed. Finally, concluding remarks are made in Section IV.

\section{MOdelling AND CONTROL}

Fig. 1 shows an overview of the studied system. The system is based on that described in [17], [19] and consists of a $400 \mathrm{MW}$ OWF connected to an onshore ac network by means of a monopolar $\mathrm{HVdc}$ link. Balanced/symmetric operation is assumed. A lumped three-phase synchronous machine (SM) with its governor and turbine, and a lumped three-phase load represent the onshore ac network. The wind power share is $25 \%$ (i.e. the OWF is rated at $400 \mathrm{MW}$, in a $1600 \mathrm{MW}$ system). The onshore HVdc terminal consists of VSCs, which control the voltage on their dc terminals and the reactive power injected into the onshore ac network. The offshore $\mathrm{HVdc}$ terminal, labelled in Fig. 1 as DR Platform, consists of two

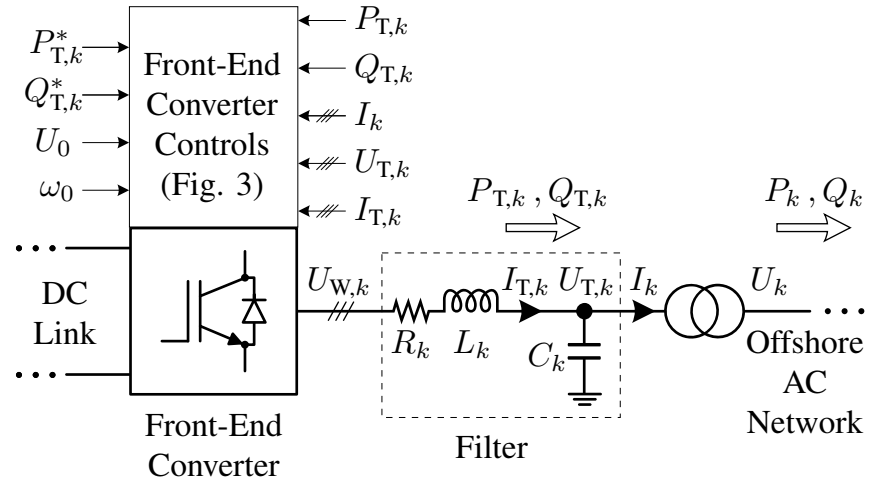

Fig. 2. $k$ th wind turbine front-end (line-side) network

(uncontrolled, line-commutated) diode-based 12-pulse rectifiers (DRs) connected in series, with corresponding reactive power compensation and filter bank on their ac side.

The OWF has 50 type-4 (full-converter) $8 \mathrm{MW}$ WTs, laid out in 6 strings. The first string, comprised of WTs $1-9$ is represented in detail. The second string, consisting of WTs $10-18$, is aggregated into an equivalent $72 \mathrm{MW}$ WT and corresponding cable equivalent $\pi$ circuit using the method proposed in [22]. Likewise, the other 4 strings, comprising WTs 19-50, are aggregated into an equivalent $256 \mathrm{MW}$ WT and corresponding cable equivalent $\pi$ circuit.

For computational efficiency, dynamics in each WT dc link and behind it are not considered, and the corresponding voltage is thus assumed constant (ideally regulated by the back-end/ machine-side converter). Pulse-width modulation (PWM) is assumed to be done in the linear range, switching effects and any delay due to implementation of the PWM are neglected, and average value models are used to represent all VSCs. Focus is given to dynamics not faster than the VSC (inner/ lower) current control loops, the fastest of which are designed to have a bandwidth of $200 \mathrm{~Hz}$. 


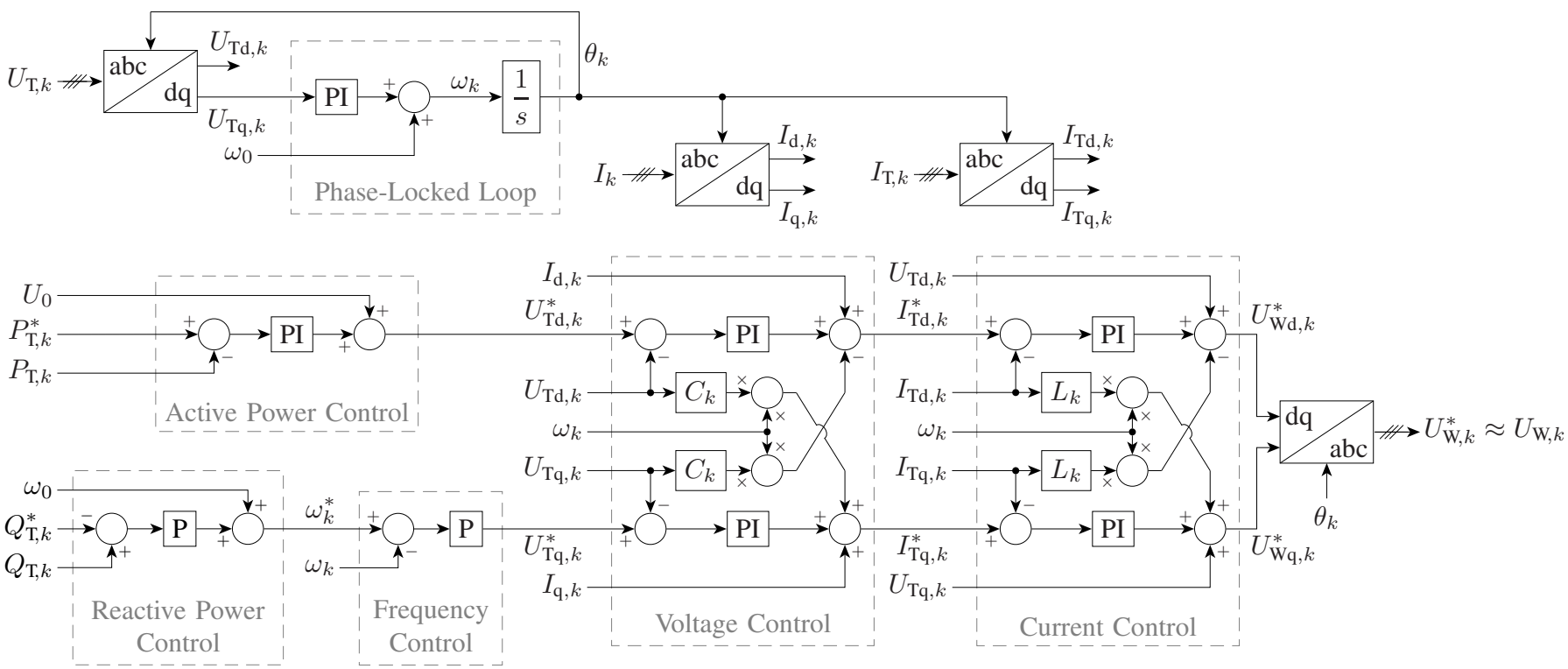

Fig. 3. $k$ th wind turbine front-end (line-side) converter controls

\section{A. Wind Turbine Front-End Converter Controls}

The front-end (line-side) network of the $k$ th wind turbine(s), $\mathrm{WT}_{k}$, is shown in Fig. 2. The WT FEC controls, shown in Fig. 3, are based on those proposed in [11] and are implemented on a rotating reference frame oriented on the voltage at the filter capacitor, $U_{\mathrm{T}, k}$.

In each WT front-end network, the filter capacitor voltage direct (d) and quadrature (q) axis components are regulated by the FEC lower/inner control loops to follow the corresponding references, $U_{\mathrm{Td}, k}^{*}, U_{\mathrm{Tq}, k}^{*}$, respectively. $U_{\mathrm{Td}, k}^{*}$ consists of two components: the offshore ac network voltage set point, $U_{0}$, common to all WTs, and a component individual to each WT, which is altered to control the FEC active power output, $P_{\mathrm{T}, k}$. In an additional control loop based on the FEC phase-locked loop (PLL), a proportional (P) controller manipulates $U_{\mathrm{Tq}, k}^{*}$ to regulate the offshore ac network frequency, $\omega$. The reference to such additional loop also consists of two components: the offshore ac network frequency set point, $\omega_{0}$, common to all WTs, and a component individual to each WT, which is altered to control the FEC reactive power output, $Q_{\mathrm{T}, k}$. When the WF is exporting power, the FEC upper/outer control loops in each WT regulate $P_{\mathrm{T}, k}$ and $Q_{\mathrm{T}, k}$ as follows. A proportional-integral (PI) controller regulates $P_{\mathrm{T}, k}$ to follow the corresponding reference, $P_{\mathrm{T}, k}^{*}$, whereas $Q_{\mathrm{T}, k}$ is controlled by a proportional $(\mathrm{P})$ regulator (reactive-power-frequency droop) with a given reference, $Q_{\mathrm{T}, k}^{*}$, so that reactive power is shared among WT FECs (avoiding overcurrents and reactive current circulation).

\section{B. Wind Farm Active Power Control}

To study the capability of such a WF to provide FS to an onshore ac network, the model is extended to include the supervisory active power control at plant level shown in Fig. 4, based on that proposed in [12] for OWFs connected to HVdc via VSCs. In the right side of Fig. 4, a PI regulator controls the

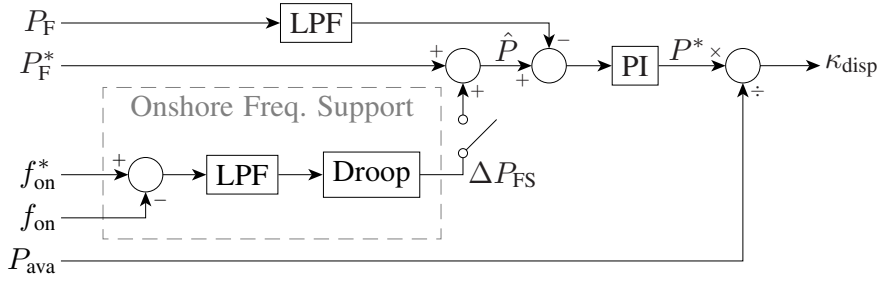

Fig. 4. Wind farm active power control

WF active power output, $P_{\mathrm{F}}$, by altering the WF active power dispatch, $P^{*}$. A first-order low-pass filter (LPF) is applied to the corresponding measurement signal. Hardware and control limits are modelled by means of corresponding restrictions on the regulator's output value and its rate of change. Proportional WF generation dispatch is used. In doing so, $P^{*}$ is divided by the overall aerodynamic power available from the wind, $P_{\text {ava }}$, to generate the OWF active power dispatch coefficient, $\kappa_{\text {disp. }}$. The active power set point of each WT FEC is then set as the product of the corresponding aerodynamic power available from the wind, $P_{\text {ava, } k}$, and the active power dispatch coefficient, i.e. $P_{\mathrm{T}, k}^{*}=\kappa_{\mathrm{disp}} P_{\mathrm{ava}, k}$.

To provide FS to the onshore ac network, the base active power reference, $P_{\mathrm{F}}^{*}$, is modified, as shown at the bottom of Fig. 4, by means of an additional active power reference, $\Delta P_{\mathrm{FS}}$, based on the onshore frequency, $f_{\mathrm{on}}$, i.e. $P^{*}=P_{\mathrm{F}}^{*}+$ $\Delta P_{\mathrm{FS}}\left(f_{\text {on }}\right) . f_{\text {on }}$ is calculated from the alternating voltage measured at the onshore HVdc terminal's point of connection with the onshore ac network and is communicated continuously to the OWF with a delay of $100 \mathrm{~ms}$. PFR is implemented by making $\Delta P_{\mathrm{FS}}$ proportional to the deviation of $f_{\text {on }}$ (to which a first-order LPF is also applied) from its nominal/reference value, $f_{\mathrm{on}}^{*}=1 \mathrm{pu}$, using a given (piecewise-defined) droop characteristic. 
TABLE I

WIND SPEED SCENARIOS CONSIDERED IN THE SIMULATIONS

\begin{tabular}{ccccccccccccc}
\hline Wind & & \multicolumn{10}{c}{ Aerodynamic power available from the wind [pu] } \\
Speed & $P_{\text {ava }}$ & $P_{\text {ava }, 1}$ & $P_{\text {ava }, 2}$ & $P_{\text {ava }, 3}$ & $P_{\text {ava }, 4}$ & $P_{\text {ava }, 5}$ & $P_{\text {ava }, 6}$ & $P_{\text {ava }, 7}$ & $P_{\text {ava }, 8}$ & $P_{\text {ava }, 9}$ & $P_{\text {ava }, 10-18}$ & $P_{\text {ava }, 19-50}$ \\
\hline Low & 0.400 & 0.930 & 0.345 & 0.421 & 0.366 & 0.344 & 0.318 & 0.299 & 0.289 & 0.289 & 0.400 \\
Medium & 0.600 & 0.987 & 0.564 & 0.644 & 0.586 & 0.562 & 0.535 & 0.515 & 0.504 & 0.504 & 0.600 & 0.600 \\
High & 1.000 & 1.000 & 1.000 & 1.000 & 1.000 & 1.000 & 1.000 & 1.000 & 1.000 & 1.000 & 1.000 & 1.000 \\
\hline
\end{tabular}

\section{Simulation RESUlts}

Results of the dynamic simulations performed in PSCAD are presented in Figs. 5-7, corresponding to onshore underfrequency events in the high, medium and low wind speed scenarios, respectively. Similar results have been obtained for onshore overfrequency events in the corresponding wind speed scenarios. Table I details the wind speed scenarios considered in the simulations. Wind speed (and the aerodynamic power available from it) is considered constant in each simulation. WF production is curtailed preventively to provide active power reserves of $0.1 \mathrm{pu}$, i.e. $P_{\mathrm{F}}^{*}=P_{\mathrm{ava}}-0.1 \mathrm{pu}$. The considered individual WT operating points in Table I take into account the wind speed deficit due to the aerodynamic interaction between WTs. In principle, $P_{\mathrm{ava}, k}$ decreases along the string in the wind speed direction [23]. All (equivalent) WT front-end networks and corresponding converter controls have the same parameter per-unit $(\mathrm{pu})$ values. Moreover, $U_{0}=0.86 \mathrm{pu}, \omega_{0}=1 \mathrm{pu}$ and $Q_{\mathrm{T}, k}^{*}=0$ for all of them.

Onshore frequency events are simulated by means of a $0.15 \mathrm{pu}$ load step change (i.e. $240 \mathrm{MW} / 1600 \mathrm{MW}$ ) at $t=$ $0.5 \mathrm{~s}$. The magnitude of each event is big enough so as to produce the maximum magnitude of $\Delta P_{\mathrm{FS}}$ in the OWF active power controller, $\max \left|\Delta P_{\mathrm{FS}}\left(f_{\mathrm{on}}\right)\right|=0.1 \mathrm{pu}$, and corresponding change in $P_{\mathrm{F}}$. Each figure includes base case responses, corresponding to no FS from the WF to the onshore ac network (i.e. the FS consisting solely of that of the SM). The (light) grey and (dark) red signals in each figure represent the base case: $\hat{P}=P_{\mathrm{F}}^{*}$, and the case in which the WF provides FS: $\hat{P}=P_{\mathrm{F}}^{*}+\Delta P_{\mathrm{FS}}$, respectively. The onshore HVdc terminal keeps the HVdc link voltage close to the corresponding set point throughout all simulations.

The OWF response to an onshore underfrequency event at high wind speed is depicted in Fig. 5. Similar results have been obtained for the other two wind speed scenarios. As can be seen in Fig. 5a, the onshore frequency response can be improved by having the OWF provide FS to the onshore ac network: by drawing on the active power reserves and increasing $P_{\mathrm{F}}$, the OWF increases $f_{\mathrm{on}}$ and maintains it at a higher value for as long as the wind allows. An increase in $P_{\mathrm{F}}$ results in an increase in the DR reactive power consumption. This is reflected in the increases in $Q_{\mathrm{F}}$ and $\omega$ in Fig. $5 \mathrm{~b}$. However, such changes are one and three orders of magnitude smaller than that in $P_{\mathrm{F}}$, respectively, while $\omega$ is kept close to $1 \mathrm{pu}$. That is the result of every grid-forming WT FEC contributing autonomously to regulating $\omega$ by means of its corresponding PLL-based proportional $(\mathrm{P})$ controller, while

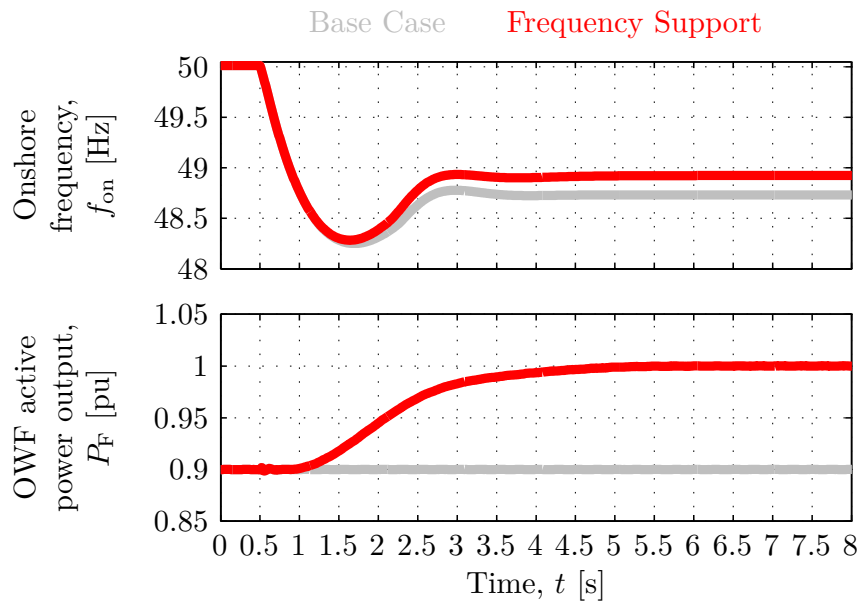

(a)
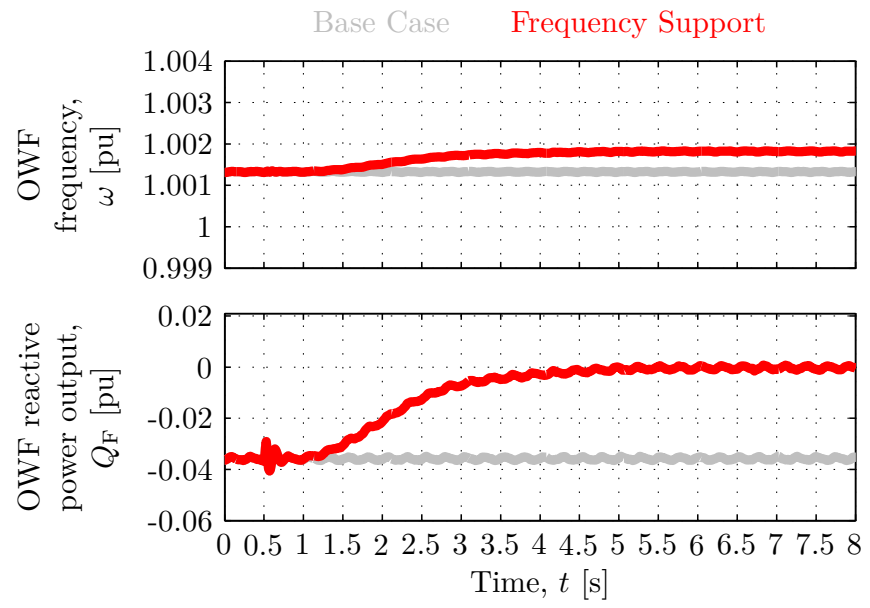

(b)

Fig. 5. Wind farm response to an onshore underfrequency event at high wind speed

sharing the reactive power with the other grid-forming WT FECs by means of its reactive-power-frequency droop ( $P$ regulator).

WT responses to an onshore underfrequency event at medium and low wind speeds are illustrated by Figs. 6 and 7, respectively. Solid, dotted and dashed traces-superimposed in the case of the WT terminal rms voltages, $U_{k}$-represent the responses of WTs 1,5 and 9, respectively, corresponding to the turbines at both ends and in the middle of the string that is represented in detail. Similar results have been obtained in the high wind speed scenario (in which $P_{\mathrm{ava}, k}=1 \mathrm{pu}$ for all 

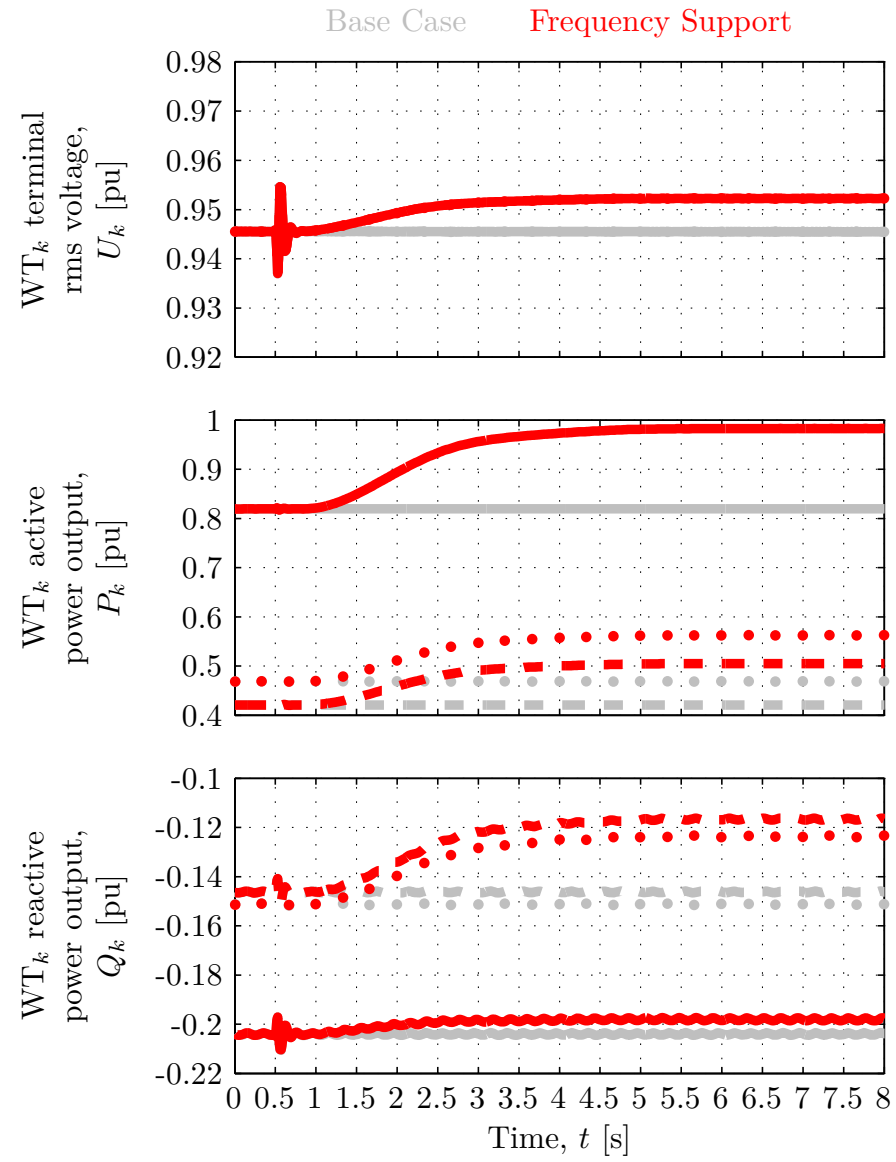

Fig. 6. $k$ th wind turbine response to an onshore underfrequency event at medium wind speed - Solid: $k=1$, Dotted: $k=5$, Dashed: $k=9$

WTs). The WT active power outputs, $P_{k}$, reflect the assumed distributions of $P_{\mathrm{ava}, k}$ (Table I) and the changes in $P^{*}$ and $\kappa_{\text {disp }}$ when FS is provided. In all wind speed scenarios, the $0.1 \mathrm{pu}$ increase in $P_{\mathrm{F}}$ in response to the onshore underfrequency event is achieved by increasing $U_{k}$ by about $7 \times 10^{-3} \mathrm{pu}$, keeping them within their normal operating range, as depicted in both figures. As shown also in both figures, the WTs share the reactive power consumption (negative values of $Q_{k}$ ) according to their power rating and their active power output, $P_{k}$.

\section{CONCLUSiOnS}

The simulation results indicate that the new connection concept does not impact the capability of OWFs to provide PFR to onshore ac networks, i.e. OWFs connected to HVdc via DRs can provide such service by means of plant-level active power controls similar to those developed for OWFs connected to HVdc via VSCs. The additional active power needed for providing such response during onshore underfrequency events can be made available by preventively curtailed OWF operation. In this way, such OWFs can reduce the onshore frequency deviation during an event and maintain it at a lower value for as long as the wind allows, while their grid-forming WTs share the reactive power consumption/production and
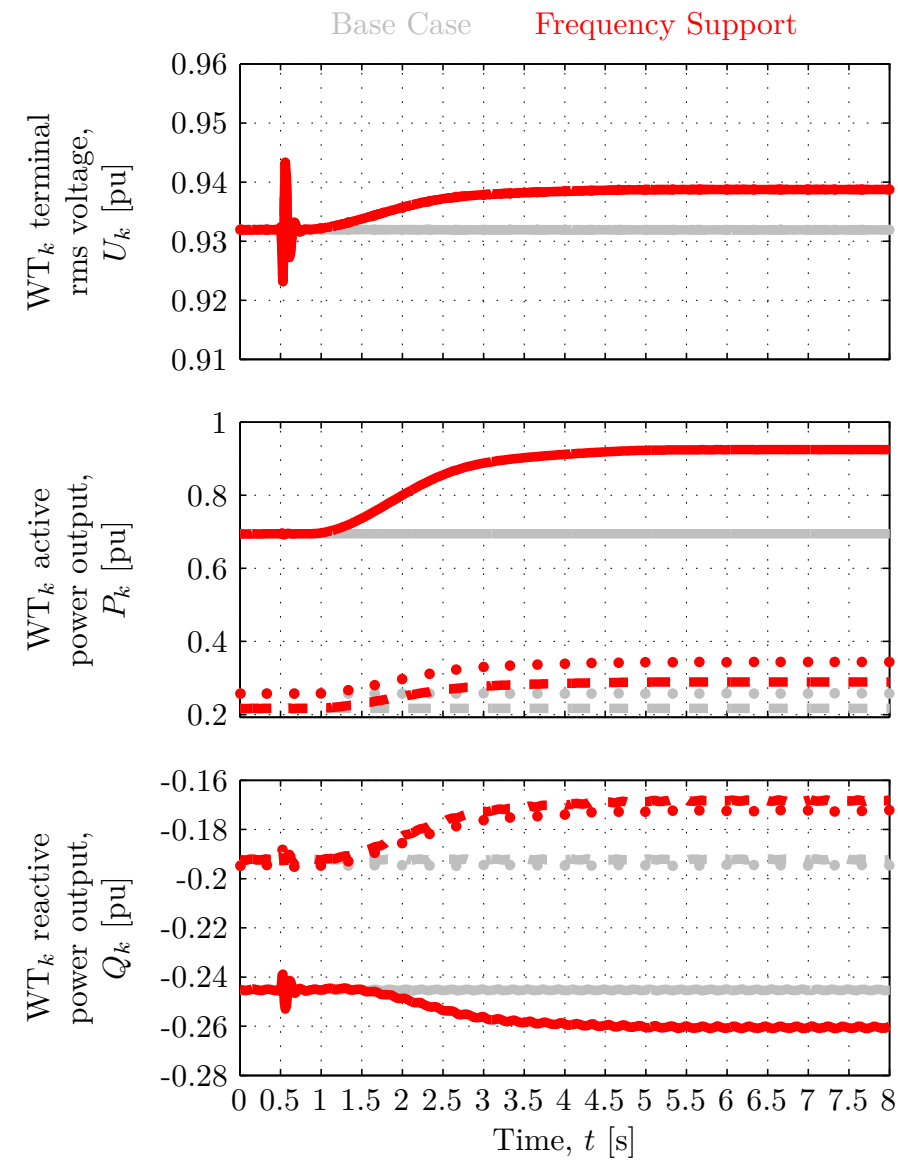

Fig. 7. $k$ th wind turbine response to an onshore underfrequency event at low wind speed - Solid: $k=1$, Dotted: $k=5$, Dashed: $k=9$

keep the offshore frequency and voltages within their normal operating ranges.

\section{ACKNOWLEDGEMENT}

The authors gratefully acknowledge the contributions of Poul E. Sørensen to the discussions leading up to this work.

\section{REFERENCES}

[1] CIGRÉ Working Group B4.55, "HVDC Connection of Offshore wind power plant," Paris, France, Technical Brochure 619, May 2015.

[2] P. Bresesti, W. L. Kling, R. L. Hendriks, and R. Vailati, "HVDC Connection of Offshore Wind Farms to the Transmission System," IEEE Transactions on Energy Conversion, vol. 22, no. 1, pp. 37-43, Feb. 2007.

[3] D. van Hertem, O. Gomis-Bellmunt, and J. Liang, Eds., HVDC Grids: For Offshore and Supergrid of the Future. Hoboken, NJ, United States: John Wiley \& Sons, Mar. 2016.

[4] ABB, "HVDC Light: It's time to connect," Tech. Rep., Mar. 2013. [Online]. Available: http://new.abb.com/ docs/default-source/ewea-doc/hvdc-light.pdf. 
[5] CIGRÉ Working Group B4.37, "VSC Transmission," Paris, France, Technical Brochure 269, Apr. 2005.

[6] R. M. Blasco-Giménez, S. C. Añó-Villalba, J. Rodríguez-D’Derlée, F. Morant-Anglada, and S. I. Bernal-Pérez, "Distributed Voltage and Frequency Control of Offshore Wind Farms Connected With a DiodeBased HVdc Link," IEEE Transactions on Power Electronics, vol. 25, no. 12, pp. 3095-3105, Dec. 2010.

[7] R. M. Blasco-Giménez, S. C. Añó-Villalba, J. Rodríguez-D’Derlée, S. I. Bernal-Pérez, and F. MorantAnglada, "Diode-Based HVdc Link for the Connection of Large Offshore Wind Farms," IEEE Transactions on Energy Conversion, vol. 26, no. 2, pp. 615-626, Mar. 2011.

[8] S. I. Bernal-Pérez, S. C. Añó-Villalba, R. M. BlascoGiménez, and J. Rodríguez-D’Derlée, "Efficiency and Fault Ride-Through Performance of a Diode-Rectifierand VSC-Inverter-Based HVDC Link for Offshore Wind Farms," IEEE Transactions on Industrial Electronics, vol. 60, no. 6, pp. 2401-2409, Jun. 2013.

[9] T. Christ, S. Seman, and R. Zurowski, "Investigation of DC Converter Nonlinear Interaction with Offshore Wind Power Park System," in Proceedings of the 2015 EWEA Offshore Conference, Copenhagen, Denmark, 10th-12th Mar. 2015.

[10] P. Menke, R. Zurowski, T. Christ, S. Seman, G. Giering, T. Hammer, W. Zink, F. Hacker, D. Imamovic, J. Thisted, P. Brogan, and N. Goldenbaum, "2nd Generation DC Grid Access for Large Scale Offshore Wind Farms," in Proceedings of the 14th Wind Integration Workshop, Brussels, Belgium, 20th-22nd Oct. 2015.

[11] L. Yu, R. Li, and L. Xu, "Distributed PLL-Based Control of Offshore Wind Turbines Connected With DiodeRectifier-Based HVDC Systems," IEEE Transactions on Power Delivery, vol. 33, no. 3, pp. 1328-1336, Jun. 2018.

[12] L. Zeni, "Power system integration of VSC-HVDC connected wind power plants: Control principles, power system services, clustering of wind power plants," PhD thesis, Technical University of Denmark, Roskilde, Denmark, Mar. 2015.

[13] J. N. Sakamuri, "Coordinated control of wind power plants in offshore HVDC grids," PhD thesis, Technical University of Denmark, Roskilde, Denmark, Mar. 2017.

[14] A. Bidadfar, O. Saborío-Romano, M. Altin, N. A. Cutululis, P. E. Sørensen, E. Prieto-Araujo, and O. GomisBellmunt, "Frequency Support Provision to Power Systems via HVDC-Based Offshore Wind Power Plants," in Proceedings of the 17th Wind Integration Workshop, Stockholm, Sweden, 17th-19th Oct. 2018.

[15] ENTSO-E, "Network Code on HVDC Connections (HVDC)," Brussels, Belgium, Network Code, Oct. 2015. [Online]. Available: https://www.entsoe.eu/majorprojects / network - code - development / high - voltage direct-current/Pages/default.aspx.
[16] — "Network Code on Requirements for Grid Connection Applicable to all Generators (RfG)," Brussels, Belgium, Network Code, Apr. 2016. [Online]. Available: https://www.entsoe.eu/major-projects/networkcode-development/requirements-for-generators/Pages/ default.aspx.

[17] PROMOTioN, "Deliverable 3.1: Detailed functional requirements to WPPs," Project Deliverable, Dec. 2016. [Online]. Available: https://www.promotion-offshore. net/fileadmin/PDFs/D3.1_PROMOTioN_Deliverable_3. 1_Detailed_functional_requirements_to_WPPs.pdf.

[18] O. Saborío-Romano, A. Bidadfar, Ö. Göksu, M. Altin, N. A. Cutululis, and P. E. Sørensen, "Connection of OWPPs to HVDC networks using VSCs and Diode Rectifiers: An Overview," in Proceedings of the 15th Wind Integration Workshop, Vienna, Austria, 15th-17th Nov. 2016.

[19] PROMOTioN, "Deliverable 3.2: Specifications of the control strategies and the simulation test cases," Project Deliverable, Mar. 2017. [Online]. Available: https :// www. promotion - offshore . net/fileadmin/PDFs/D3.2_ Specifications_Control_strategies_and_simulation_test_ cases.pdf.

[20] O. Saborío-Romano, A. Bidadfar, Ö. Göksu, and N. A. Cutululis, "Frequency Support from OWPPs connected to HVDC via Diode Rectifiers," in Proceedings of the 16th Wind Integration Workshop, Berlin, Germany, 25th-27th Oct. 2017.

[21] PROMOTioN, "Deliverable 3.5: Performance of ancillary services provision from WFs connected to DRHVDC," Project Deliverable, Jan. 2018. [Online]. Available: https://www. promotion- offshore.net/fileadmin/ PDFs/D3.5_PROMOTioN_Performance_of_ancillary_ services_pro-vision_from_WFs_connected_to_DR HVDC.pdf.

[22] E. Muljadi, S. Pasupulati, A. Ellis, and D. Kosterov, "Method of Equivalencing for a Large Wind Power Plant with Multiple Turbine Representation," in Proceedings of the IEEE PES 2008 General Meeting, Pittsburgh, PA, United States, 20th-24th Jul. 2008.

[23] T. Göçmen, P. van der Laan, P. E. Réthoré, A. PeñaDíaz, G. C. Larsen, and S. Ott, "Wind turbine wake models developed at the technical university of Denmark: A review," Renewable and Sustainable Energy Reviews, vol. 60, pp. 752-769, Jul. 2016. 